\title{
Post-abortion contraception: care and practices $^{1}$
}

\author{
Ana Luiza Vilela Borges² \\ Renata Luciria Monteiro ${ }^{3}$ \\ Luiza Akiko Komura Hoga ${ }^{4}$ \\ Elizabeth Fujimori ${ }^{4}$ \\ Christiane Borges do Nascimento Chofakian ${ }^{5}$ \\ Osmara Alves dos Santos ${ }^{6}$
}

Objective: to analyze assistance regarding contraception methods received by women during hospitalization due to abortion, and contraceptive practices the month after this episode. Methods: a longitudinal study of women hospitalized due to abortion in a public hospital in the city of São Paulo. Face-to-face interviews $(n=170)$ followed by telephone interviews in the subsequent month $(n=147)$ were conducted between May and December of 2011. Results: a small number of women reported they received guidance on, and prescription for, contraceptive methods at hospital discharge. A trend of statistical significance was identified for prescription of contraceptive methods at discharge and its use in the following month, when adjusted for age. Most women reported sexual intercourse (69.4\%) with the use of contraceptive method $(82.4 \%)$, but no health professional guidance $(63.1 \%)$. Conclusion: despite the fact that postabortion contraception assistance was lower than the recommended guidelines by public health policies, women demonstrated willingness to use contraceptive methods.

Descriptors: Contraception; Abortion; Health Care (Public Health).

\footnotetext{
${ }^{1}$ Supported by Apoio financeiro da Fundação de Amparo à Pesquisa do Estado de São Paulo (FAPESP), process \# 2010/15298-0.

2 PhD, Professor, Escola de Enfermagem, Universidade de São Paulo, São Paulo, SP, Brazil.

${ }^{3}$ RN.

${ }^{4} \mathrm{PhD}$, Associate Professor, Escola de Enfermagem, Universidade de São Paulo, São Paulo, SP, Brazil.

${ }^{5}$ Doctoral student, Escola de Enfermagem, Universidade de São Paulo, São Paulo, SP, Brazil.

${ }^{6}$ Master's student, Escola de Enfermagem, Universidade de São Paulo, São Paulo, SP, Brazil.
}

Corresponding Author:

Ana Luiza Vilela Borges

Universidade de São Paulo. Escola de Enfermagem

Av. Dr. Enéas de Carvalho Aguiar, 419

CEP: 05403-000, São Paulo, SP, Brasil

E-mail: alvilela@usp.br
Copyright () 2014 Revista Latino-Americana de Enfermagem This is an Open Access article distributed under the terms of the Creative Commons Attribution Non-Commercial License (CC BY-NC).

This license lets others distribute, remix, tweak, and build upon your work non-commercially, and although their new works must also acknowledge you and be non-commercial, they don't have to license their derivative works on the same terms. 


\section{Introduction}

In 2011, the Ministry of Health ${ }^{(1)}(\mathrm{MoH})$ revised the Guidelines for Comprehensive Abortion Care, aiming to standardize and qualify women's health care. Aside from the abortion or miscarriage itself, qualified care to women who experience such an episode is considered a priority, primarily to minimize unfavorable outcomes such as maternal and neonatal death - a major challenge that persists in the current health care context ${ }^{(1)}$. The priority of abortion care emerged, among other aspects, as a result of the need to follow the propositions of the Cairo and Beijing Conferences and reach the targets set by the Millennium Development Goals(2), which include the reduction of the maternal mortality ratio in Brazil, which is close to $60^{(3)}$.

The conceptual framework for abortion care supporting the aforementioned guideline recommends that an integrated network of health care services should be available to women in order to meet their physical and psychological needs, considering their social background. Also, it was recommended that family planning services should be offered during hospitalization, to ensure the provision of appropriate guidance for women who wish to become pregnant again, and to prevent new episodes of abortion.

This object of study for article was post-abortion contraceptive practices, considering the complexity of the relationship between contraception and abortion. In most cases, women who experienced miscarriage planned to become pregnant again as soon as possible; while those who experienced abortion probably did not have such intention. Whatever the personal desires of these women, the adoption of measures to provide autonomy and freedom over reproductive planning decisions is important at this moment that is experienced by women.

The World Health Organization (WHO) $)^{(4)}$ and the International Federation of Gynecology and Obstetrics $(\mathrm{IFGO})^{(5)}$ recommend that women who experience abortion should receive contraception assistance, so they can become pregnant in appropriate clinical conditions for the proper development of pregnancy. This requires a minimal interpregnancy interval of six months, mainly to minimize the risk of adverse health outcomes for women and children, such as maternal anemia, premature birth, and low birth weight. These outcomes are widely recognized as associated with an interpregnancy interval lower than six months(6).

The $\mathrm{MoH}^{(1)}$ recommends that contraceptive methods (CM) should be available at the same health facility where women receive care during the abortion process. This position is based on the fact that $75 \%$ of women restart the ovulation process within six weeks after the occurrence of abortion(4), indicating the need for early initiation of contraceptive counseling.

Although the relevance of contraceptive assistance is an aspect of comprehensive care for women during the abortion process, there is a lack of knowledge about the contraceptive practices adopted by them. This fact was considered as the rationale for this research, which aimed to analyze the contraception assistance received by women during hospitalization due to abortion, and the contraceptive practices adopted by them the month after this episode. We hypothesized that access to contraceptive care during post-abortion hospitalization was associated with the use of $\mathrm{CM}$ the month after this episode.

\section{Methods}

The data presented in this article was part of a broader longitudinal quantitative study aimed to assess contraceptive practices adopted by women during the first six months after hospitalization due to abortion. This article focuses on data regarding contraceptive assistance received during hospitalization, and practices adopted during the first month after the abortion.

The study population was composed of a nonprobabilistic sample of women hospitalized due to abortion at a public hospital in the city of São Paulo, between May and December of 2011. All women hospitalized due to abortion were invited to participate in this study. Data were collected through individual face-to-face interviews during hospitalization (Time 0 ) and by telephone, 30 days after discharge (Time 1). Women who did not have a telephone (landline or mobile) and who could not establish a dialogue in Portuguese were excluded. This criteria was established because many women attended by this institution are immigrants from countries whose native language is not Portuguese.

Nurse midwives, who were trained to collect data through subject interviews, performed data collection at Time 0. Two experienced researchers in the field of sexual and reproductive health, who were also experts in the development of telephone interviews, were responsible for conducting the interviews at Time 1 . A total number of 184 women were invited to participate in the study at Time 0 . Of these, 14 refused (eight did not justify their refusal, and the others reported difficulty in sharing 
personal and intimate information). This resulted in 170 women participating in the first interview at Time 0 . At Time 1, there were 23 losses, caused by: one maternal death, 15 women who could not be reached by phone (number did not exist), did not answer calls, or could not be found at the reported phone number; and seven refusals. This resulted in 147 women participating in the study. There were no statistically significant differences between losses and those who remained in the study for Time 1 in relation to age, pregnancy planning or previous abortion.

Structured questionnaires were used to collect data. The questionnaire used at Time 0 contained questions about social, demographic and reproductive data and specific questions to classify pregnancy planning. The original questionnaire was translated into Portuguese and validated for the Brazilian culture(7). The reproductive data were related to contraceptive assistance received during hospitalization, the use of $\mathrm{CM}$ during the month after abortion, in addition to questions about the last menstrual period and the possibilities of becoming pregnant again. As abortion is legally restricted in Brazil, we did not question the etiology of the pregnancy termination, since this fact could result in underestimation of data.

Data were analyzed using the Statistical Package for Social Sciences (SPSS) version 17.0 for Windows. Descriptive techniques, along with univariate and multivariate analyses were used for data analysis. The quantitative variables were described by mean and standard deviation, and absolute and relative frequencies were calculated for qualitative variables. The differences between two proportions were analyzed using the chi-square test and Fisher's exact test. The description of the interval between abortion and the first period (in days) was calculated using the KaplanMeier technique.

The multivariate logistic regression method was used for the analysis of association between the dependent variable (using CM 30 days after the abortion) and the following independent variables: CM prescribed during hospitalization (yes / no); CM counseling during hospitalization (yes / no); age (15-24, 25-34 and >35); paid work (yes / no); marital status (living / not living with partner); children (yes / no); previous abortion (yes / no); planned pregnancy (yes / no, or ambiguous); and, intention to become pregnant again (no / yes / no thoughts about it).

The independent variables were analyzed using multiple logistic regression only when presenting a p-value of $<0.20$ in the previous univariate analysis results, regarding use of $\mathrm{CM} 30$ days after abortion. The entry of each variable in the model had the following sequence: 1 ) independent variable of interest according to the study hypothesis (CM prescription and CM guidance during hospitalization) entered into the model; 2) statistical significance, i.e., those that had lower $\mathrm{p}$-value were allocated first into the model. The Hosmer-Lemeshow test was used to analyze the model adjustment.

The project was approved by two Research Ethics Committees accredited by the National Council on Ethics in Research (CONEP), with one of them being at the study setting. All ethical rules determined by CONEP were followed. Women aged less than 18 years were authorized by their parent or guardian to participate in the study. Women themselves defined the best time to receive phone calls and answer the interview questions. In the data collection instrument there was a specific field where the woman could indicate the possibility of leaving a message, and with whom the interviewers could talk about the research. Such indications were strictly followed.

\section{Results}

The mean age of the women was 29 years old $(\mathrm{SD}=7.5)$. Twelve $(7.0 \%)$ were 17 years old or less. Regarding schooling, they had a mean of 9.2 years of study $(S D=2.5)$; two had completed a university degree and six had begun one, and one woman was illiterate.

Almost half of the women were classified as black or mixed race $(48.8 \%)$. Over half of interviewees had a role within the job market at the time of the interview $(59.4 \%) ; 43.5 \%$ reported being Catholic. Regarding sexual behavior and reproductive history, $75.3 \%$ lived with a partner who had a mean age of 32.7 years $(\mathrm{SD}=8.7)$. About two thirds $(68.2 \%)$ had children. For three quarters $(75.3 \%)$, this was the first experience of abortion, and $22.4 \%$ of the total reported an unplanned pregnancy that resulted in abortion. Some of these data are presented in Table 1.

Almost half of the women (45.3\%) reported having menstruated in the first month post-abortion, after a mean of 28.5 days ( $95 \%$ CI $=27.4$ to 29.6), with a median of 29.0 days. Figure 1 shows the distribution of women according to the time interval (days) between the hospitalization and return of the menses. 
Table 1 - Social, demographic and reproductive characteristics of study subjects, São Paulo, SP, Brazil, 2012

\begin{tabular}{lcc}
\hline \multicolumn{1}{c}{ Characteristics } & $\mathbf{n}$ & $\%$ \\
\hline Age (years) & 54 & 31.8 \\
$15-24$ & 69 & 40.6 \\
$25-34$ & 47 & 27.6 \\
$\geq 35$ & & \\
Ethnicity & 79 & 46.5 \\
White & 57 & 33.5 \\
Mixed & 26 & 15.3 \\
Black & 6 & 3.5 \\
Asian & 2 & 1.2 \\
Indigenous & & \\
Paid work & 69 & 40.6 \\
No & 101 & 59.4 \\
Yes & & \\
Marital status & 128 & 75.3 \\
Living with a partner & 42 & 24.7 \\
Living without a partner & & (continue...)
\end{tabular}

(continue...)
Table 1 - (continuation)

\begin{tabular}{lcc}
\hline \multicolumn{1}{c}{ Characteristics } & $\mathbf{n}$ & $\%$ \\
\hline Religion & & \\
Catholic & 74 & 43.5 \\
Protestant & 50 & 29.4 \\
None & 34 & 20.0 \\
$\quad$ Others & 12 & 7.1 \\
Children & & \\
$\quad$ No & 54 & 31.8 \\
$\quad$ Yes & 116 & 68.2 \\
Previous abortion & & \\
$\quad$ No & 42 & 24.7 \\
$\quad$ Yes & 128 & 75.3 \\
Planned pregnancy & & \\
$\quad$ No & 38 & 22.4 \\
Ambiguous & 82 & 48.2 \\
$\quad$ Yes & 50 & 29.4 \\
Total & 170 & 100.0 \\
\hline
\end{tabular}

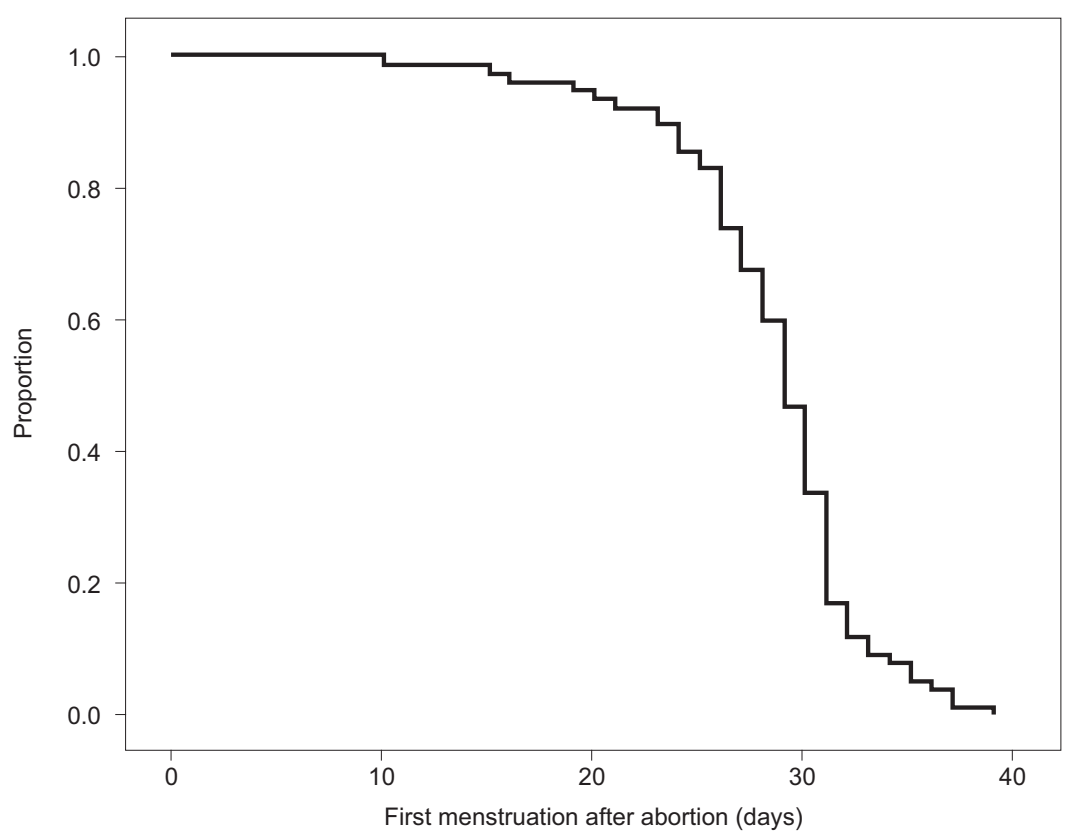

Figure 1 - Distribution of study subjects according to the time interval between hospital discharge and return of menses. São Paulo, SP, Brazil, 2012

Regarding health care and contraceptive practices, only $33.3 \%$ of women were counseled during hospitalization, and a lower proportion (8.9\%) was discharged with a prescription for CM. During the first month after hospitalization, $25.9 \%$ of women received counseling on CM use, not always provided by health professionals. Most of the women reported sexual intercourse with the use of CM during the first month after abortion (Table 2). The most frequently used CM was the male condom, followed by the contraceptive pill, with an initiation starting at a mean of 15 days (SD = 10.9) after hospital discharge (data not shown in the table below). 
Table 2 - Contraceptive counseling received during hospitalization due to abortion and contraceptive practices during the subsequent month. São Paulo, SP, Brazil, 2012

\begin{tabular}{|c|c|c|}
\hline Variable & $\mathbf{n}$ & $\%$ \\
\hline \multicolumn{3}{|l|}{ During hospitalization $(n=170)$} \\
\hline Counseling on contraceptive methods & 49 & 33.3 \\
\hline Prescription for contraceptive method & 13 & 8.9 \\
\hline \multicolumn{3}{|l|}{ During the subsequent month of abortion $(n=147)$} \\
\hline Were you counseled about contraception methods? & 38 & 25.9 \\
\hline \multicolumn{3}{|l|}{ Counseling setting } \\
\hline Primary Health Care service & 24 & 63.2 \\
\hline At home & 10 & 26.3 \\
\hline Ambulatory service & 3 & 7.9 \\
\hline Private practice & 1 & 2.6 \\
\hline \multicolumn{3}{|l|}{ Who provided the counseling? } \\
\hline Physician & 27 & 71.1 \\
\hline Family and friends & 10 & 26.3 \\
\hline Nurse & 1 & 2.6 \\
\hline Did you have sexual intercourse? & 102 & 69.4 \\
\hline Did you use a contraceptive method? & 84 & 82.4 \\
\hline For all intercourse & 77 & 91.7 \\
\hline For some intercourse & 7 & 8.3 \\
\hline Did you use contraceptive methods without counseling from a health professional? & 53 & 63.1 \\
\hline Did you buy a contraceptive method in a private pharmacy? & 49 & 58.3 \\
\hline
\end{tabular}

When questioned about the desire for a new pregnancy one month after hospitalization, the majority $(61.8 \%)$ reported that they intended to become pregnant again in some point of their life; nearly a fifth $(19.2 \%)$ did not wish to get pregnant again, and a similar proportion (19.0\%) had no thoughts about it (data not shown in the table).

Variables presenting a p-value of $<0.20$ were included in the multiple logistic regression analysis along with the prescription of CM. They were: age, marital status and paid work. In the multivariate analysis, the age-adjusted prescription of CM was maintained, as this was the only variable that presented a significant association with the use of CM the month after abortion (Table 3).

The variable "CM counseling during hospitalization", despite being part of the hypothesis, was not retained in the final multiple regression model because it did not present significance, nor did it improve or modify the model adjustment.

Table 3 - Number, proportion and aspects associated with the use of CM 30 days after abortion (univariate analysis and multiple logistic regression), São Paulo, SP, Brazil, 2012

\begin{tabular}{|c|c|c|c|c|c|c|}
\hline \multirow{3}{*}{ Variable } & \multirow{3}{*}{ Category } & \multicolumn{3}{|c|}{ Univariate analysis } & \multicolumn{2}{|c|}{$\begin{array}{l}\text { Multiple logistic } \\
\text { regression analysis }\end{array}$} \\
\hline & & \multicolumn{3}{|c|}{$\begin{array}{l}\text { Use of contraceptive methods } \\
30 \text { days after abortion }\end{array}$} & \multicolumn{2}{|c|}{ Final model } \\
\hline & & $\mathbf{n}$ & $\%$ & $\mathrm{p}$ & OR adjust* & IC 95\% \\
\hline \multirow[t]{3}{*}{ CM prescription at hospital discharge } & & & & 0.074 & & \\
\hline & No & 76 & 87.4 & & 1.0 & - \\
\hline & Yes & 11 & 12.6 & & 4.7 & {$[0.9-22.9]$} \\
\hline \multirow[t]{3}{*}{$\mathrm{CM}$ counseling during hospitalization period } & & & & 0.722 & & \\
\hline & No & 57 & 65.5 & & & \\
\hline & Yes & 30 & 34.5 & & & \\
\hline \multirow[t]{4}{*}{ Age } & & & & 0.019 & & \\
\hline & $15-24$ & 20 & 22.9 & & 1.0 & - \\
\hline & $25-34$ & 44 & 50.6 & & 3.3 & [1.4-7.5] \\
\hline & $\geq 35$ & 23 & 26.5 & & 1.8 & {$[0.7-4.3]$} \\
\hline
\end{tabular}


Table 3 - (continuation)

\begin{tabular}{|c|c|c|c|c|c|c|}
\hline \multirow{3}{*}{ Variable } & \multirow{3}{*}{ Category } & \multicolumn{3}{|c|}{ Univariate analysis } & \multirow{2}{*}{\multicolumn{2}{|c|}{$\begin{array}{c}\begin{array}{c}\text { Multiple logistic } \\
\text { regression analysis }\end{array} \\
\text { Final model }\end{array}$}} \\
\hline & & \multicolumn{3}{|c|}{$\begin{array}{l}\text { Use of contraceptive methods } \\
30 \text { days after abortion }\end{array}$} & & \\
\hline & & $\mathrm{n}$ & $\%$ & p & OR adjust* & IC $95 \%$ \\
\hline Paid employment & & & & 0.180 & & \\
\hline & No & 31 & 35.6 & & & \\
\hline & Yes & 56 & 64.4 & & & \\
\hline Marital status & & & & 0.041 & & \\
\hline & Living with a partner & 72 & 82.8 & & & \\
\hline & Not living with a partner & 15 & 17.2 & & & \\
\hline Children & & & & 0.223 & & \\
\hline & No & 25 & 28.7 & & & \\
\hline & Yes & 62 & 71.3 & & & \\
\hline Previous abortion & & & & 0.851 & & \\
\hline & No & 65 & 74.7 & & & \\
\hline & Yes & 22 & 25.3 & & & \\
\hline Planned pregnancy & & & & 0.838 & & \\
\hline & No & 17 & 19.5 & & & \\
\hline & Ambiguous & 44 & 50.9 & & & \\
\hline & Yes & 26 & 29.9 & & & \\
\hline Desire to become pregnant again & & & & 0.776 & & \\
\hline & No & 17 & 19.5 & & & \\
\hline & Yes & 55 & 63.2 & & & \\
\hline & No thoughts about it & 15 & 17.2 & & & \\
\hline
\end{tabular}

* Hosmer-Lemeshow test $=0.919$

\section{Discussion}

Results showed that approximately two weeks post-abortion, many women were already vulnerable to a new pregnancy, although fewer than a half of them menstruated the month after abortion. These data support the possibility of ovulation and return of fertility around two weeks post-abortion ${ }^{(4,8)}$. Most women had resumed sexual activity at this stage, not always with proper use of CM, corroborating the results of another study ${ }^{(9)}$. This situation highlights the contraceptive vulnerability to which women were subject in the month after abortion.

The only variable that was associated with the use of CM was the woman's age (between 25 and 34 years). These women were 2.3 times more likely to use CM compared to young women (below 24 years). It was found that this association was independent of reproductive history, unplanned pregnancy, or future reproductive intentions. As it is not clear how age influenced the decision of using $\mathrm{CM}$ in the postabortion period, this result should not be interpreted in isolation, as it could lead to hasty conclusions about an event that was socially influenced - in this case, the use of CM.
The multiple logistic regression model revealed that CM prescription during hospitalization was very close to reaching statistical significance, indicating a probable influence on the use of CM the month after abortion. The excessively wide confidence interval suggests that the number of women in this group was small. In fact, only 13 women reported they were discharged with a prescription for CM. Findings of a study ${ }^{(10)}$ in three capitals of Northeastern Brazil showed that support for women during the abortion process is still weak, and the actions to ensure continuity of care - among them, the contraception counseling - was the least cited. Therefore, it seems that the contraceptive care recommendations of the revised $\mathrm{MoH}$ guideline(1) have not reached a level of full compliance. Interestingly, the counseling about CM during hospitalization showed no influence on their later use, which indicated that care should not only be based on counseling about CM importance or manners of use, but also should include the supply of CM inputs.

In fact, studies have shown that the adoption rate of contraceptive in the post-abortion period is higher when inputs are offered during hospitalization ${ }^{(11-12)}$. Other studies also emphasize that both counseling and offering of $\mathrm{CM}$ during this period increased the chance of 
use in the subsequent months ${ }^{(13-15)}$. Thus, hospitalization, though brief, seems to be the most propitious time to develop actions that meet the women's needs(16), including those related to the use of CM.

After hospital discharge, only one out of four women received counseling on how to prevent pregnancy. This result highlighted the lack of continuity in care in the post-abortion period, reflecting the absence of comprehensiveness in the care provided to these women, as previously described(17).

The proportion of women who reported sexual intercourse was higher than the proportion of woman who reported $\mathrm{CM}$ use the month after abortion. The CM adopted after abortion was similar to those used by the majority of Brazilian women(18), which were the contraceptive pill and male condom. Moreover, it is noteworthy that about half of the time, the CM was purchased in private pharmacies, without any guidance from a health professional. Although many women took the initiative to use CM during the first month after abortion, and obtained inputs to prevent another pregnancy, one cannot deny that some remained vulnerable to pregnancy during this period, even if they reported their intention not to become pregnant again.

Although this study highlighted interesting findings regarding the contraceptive assistance and practices in the post-abortion period, it is important to emphasize that it was not possible to conclude whether women who experienced abortion would adopt different practices in this area, or whether other public or private hospitals would have provided the same kind of attention. The fact that this study was conducted with nonprobability sampling did not allow the generalization of these findings.

It is important to highlight that the development of a longitudinal study is permeated by challenges, such as the need to ensure as few losses as possible. Given the fact that this study focused on a delicate matter that is a controversial subject in the Brazilian context, and that literature ${ }^{(19)}$ recommend that losses in quantitative studies should not exceed $20 \%$, the losses in this study were considered acceptable (13.8\%).

\section{Conclusion}

Few women were discharged from hospital postabortion with a $\mathrm{CM}$ prescribed, so the $\mathrm{MoH}$ guidelines in relation to health care in post-abortion contraception were not fulfilled. Many women adopted $\mathrm{CM}$ in the subsequent post-abortion month, which showed a desire to adopt measures to postpone a new pregnancy, regardless of whether or not they received professional support. The prescription of CM at hospital discharge adjusted for age - showed a trend of association with the use of CM the month after abortion. This data showed the importance of contraceptive assistance and practices in the post-abortion period.

\section{References}

1. Ministério da Saúde (BR). Atenção Humanizada ao Abortamento. Norma Técnica. Série Direitos Sexuais e Direitos Reprodutivos - Caderno no 4. 2.ed. Brasília: Ministério da Saúde; 2011.

2. Victora $\mathrm{CS}$, Aquino $\mathrm{EML}$, Leal $M C$, Monteiro $C A$, Barros FA, Szwarcwald CL. Saúde de mães e crianças no Brasil: progressos e desafios. Lancet. 2011; 6736(11):60138-4.

3. World Health Organization. Trends in maternal mortality: 1990 to 2010. WHO, UNICEF, UNFPA and The World Bank estimates. Genebra: WHO; 2012.

4. World Health Organization. Report of a WHO Technical Consultation on Birth Spacing. Genebra: WHO; 2006.

5. Federação Internacional de Ginecologia e Obstetrícia. Planejamento familiar: componente-chave no atendimento pós-abortamento [Internet]. FIGO. 2009. [acesso 13 jan 2013]; Disponível em: http://www. esdproj.org/site/DocServer/PAC_FP_consensus_report_ Port_final_for_web.pdf?docID $=3162$

6. Conde-Agudelo A, Belizán IM, Breman R, Brockman SC, Rosas-Bermudez A. Effect of the interpregnancy interval after an abortion on maternal and perinatal health in Latin America. Int J Gyn Obst. 2005;89:s34-s40.

7. Borges ALV, Cavalhieri FB, Hoga LAK, Fujimori E, Barbosa LR. Planejamento da gravidez: prevalência e aspectos associados. Rev EsC Enferm USP. 2011;45(spe2):1679-84.

8. Wilcox AJ, Dunson D, Baird DD. The timing of the "fertility window" in the menstrual cycle: day specific estimates from a prospective study. $\mathrm{Br}$ Med $\mathrm{J}$. 2000;321(7271):1259-62.

9. Boesen HC, Rörbye C, Närgaard M, Nilas L. Sexual behavior during the first eight weeks after legal termination of pregnancy. Acta Obstet Gynecol Scand. 2004;83(12):1189-92.

10. Aquino EML, Menezes G, Barreto-de-Araújo TV, Alves MT, Alves SV, Almeida MCC, et al. Qualidade da atenção ao abortamento no Sistema Único de Saúde do Nordeste brasileiro: o que dizem as mulheres? Ciênc Saúde Coletiva. 2012;17(7):1765-76. 
11. Schunmann C, Glasier A. Specialist contraceptive counselling and provision after termination of pregnancy improves uptake of long-acting methods but does not prevent repeat abortion: a randomized trial. Hum Reprod. 2006;21(9):2296-2303.

12. Ferreira ALCG, Souza AI, Lima RA, Braga C. Choices on contraceptive methods in post-abortion family planning clinic in the northeast Brazil. Rep Health. $2010 ; 7(5): 1-5$.

13. McDougall J, Fetters $T$, Clark KA, Rathavy $T$. Determinants of contraceptive acceptance among Cambodian abortion patients. Stud Fam Plann. 2009;40(2):123-32.

14. Kestler E, Barrios B, Hernández EM, del Valle V, Silva A. Humanizing access to modern contraceptive methods in national hospitals in Guatemala, Central America. Contraception. 2009;80(1):68-73.

15. Ferreira AL, Souza AI, Pessoa RE, Braga C. The effectiveness of contraceptive counseling for women in the postabortion period: an intervention study. Contraception. 2011;84(4):377-83.

16. Mariutti MG, Almeida AM, Panobianco MS. Nursing care according to women in abortion situations. Rev. Latino-Am. Enfermagem. 2007;15(1):20-6.

17. Koch C, Santos C, Santos MR. Study of the measurement properties of the Portuguese version of the Well-Being Questionnaire 12 (W-BQ12) in women with pregnancy loss. Rev. Latino-Am. Enfermagem. 2012;20(3):567-74.

18. Ministério da Saúde (BR). PNDS 2006. Pesquisa Nacional de Demografia e Saúde da Criança e da Mulher. Relatório. Brasília: Ministério da Saúde; 2008.

19. Babbie E. Métodos de pesquisa de survey. Belo Horizonte: Ed. UFMG; 2001. 519 p. 